\title{
Glucocorticoid receptor mediated the propofol self-administration by dopamine D1 receptor in nucleus accumbens
}

Binbin Wu M.D, Ph.D ${ }^{1}$, Yuyuan Liang M.D ${ }^{1}$, Zhanglei Dong M.D ${ }^{1}$, Zhichuan Chen M.D ${ }^{1}$, Gaolong Zhang M.D ${ }^{1}$, Wenxuan Lin M.D ${ }^{1}$, Sicong Wang M.D ${ }^{1}$, Benfu Wang M.D ${ }^{1}$, Ren-Shan Ge, M.D ${ }^{1} *$, Qingquan Lian, M.D, Ph.D ${ }^{1}$.

1. Department of Anesthesiology and Pain Medicine, the Second Affiliated Hospital of Wenzhou Medical University, Wenzhou, China, 325027.

Corresponding Authors:

Prof. Ren-Shan Ge, MD; Department of Anesthesiology and Pain Medicine, the Second Affiliated Hospital of Wenzhou Medical University, 109 Xueyuan West Road, Wenzhou, Zhejiang 325027, China. Tel: +86 0577-88832469, Fax: +86 0577-88879167, Email: raygee0828@163.com

Prof. Qingquan Lian MD, PhD; Department of Anesthesiology and Pain Medicine, the Second Affiliated Hospital of Wenzhou Medical University, 109 Xueyuan West Road, Wenzhou, Zhejiang 325027, China. Tel: +86 0577-88002927, Fax: +86 0577-88879167, Email: lianqingquanmz@163.com

\begin{abstract}
Abbreviations: GR, glucocorticoid receptors; GC, glucocorticoids; NAc, the nucleus accumbens; VTA, ventral tegmental area; FR1, the fixed ratio 1; MR, mineralocorticoid receptor; ACTH, adrenocorticotropic hormone; HPA hypothalamic-pituitary-adrenal axis; D1 receptor, dopamine D1 receptor; D2 receptor , dopamine D2 receptor; ANOVA, analysis of variance.
\end{abstract}




\section{Abstract}

Propofol, a widely used anesthetic, can cause addictive behaviors in both human and experimental animals. In present study, we examined the involvement of glucocorticoid receptor (GR) signaling in the molecular process by which propofol may cause addiction. The propofol self-administration model was established by a fixed ratio 1 (FR1) schedule of reinforced dosing over a successive 14 days in rats. On day 15 , the rats were treated with dexamethasone, a GR agonist $(10-100 \mu \mathrm{g} / \mathrm{kg})$, or RU486, a GR antagonist (10-100 $\mu \mathrm{g} / \mathrm{kg})$ at 1 hour prior to the last training. The animal behaviors were recorded automatically by the computer. The expression of dopamine D1 receptor in the NAc was examined by Western blot and the concentrations of plasma corticosterone were measured by ELISA. To further examine the specificity of GR in the process, mineralocorticoid receptor (MR) antagonist, spironolactone, and dexamethasone plus MR agonist, aldosterone, were also tested. Administration of dexamethasone $(100 \mu \mathrm{g} / \mathrm{kg})$ or RU486 $(\geq 10 \mathrm{mg} / \mathrm{kg})$ significantly attenuated the rate of propofol maintained active nose-poke responses and infusions, which were accompanied by reductions in both plasma corticosterone level and the expression of D1 receptor in the NAc. Neither spironolactone alone nor dexamethasone combined with aldosterone affected the propofol-maintaining self-administrative behavior, indicating GR, but not MR, modulates the propofol reward in rats. In addition, neither the food-maintaining sucrose responses under FR1 schedule nor the locomotor activity was affected by any doses of dexamethasone or RU486 tested. These findings provide evidence that GR signaling may play an 
important role in propofol reward.

Key words: corticosterone; dexamethasone; D1 receptor; propofol; self-administration 


\section{Introduction}

Drug abuses and addictions have been major social and health concerns. In order to effectively prevent and treat drug abuses, it becomes increasingly important for us to know how addictive drugs work. Propofol, an intravenous anesthetic, has been widely used in the clinic due to its characteristics of short action as well as quick and smooth recoveries compared with other anesthetics. However, in recent years, propofol has been considered an addictive drug in anesthesiology, as increasing reports showed that propofol was capable of inducing pleasure, euphoria, and dependence. A clinical survey of 126 academic anesthesiology programs in the United States during 1995-2005 has found that $18 \%$ of the departments showed propofol abuse with the incidence of $1 \%$ (Wischmeyer et al., 2007). Also, other clinical studies have suggested that even second-hand exposure to aerosolized propofol for elongated time in operation room increased sensitization and created a risk factor for the occupational addiction (McAulliffe et al., 2006). In the animal studies, the reinforcing property of propofol was confirmed by animal experiments, in which repeated doses of propofol led to addictive behavior of rats with conditioned place preference and self-administration tests (Lesage et al., 2000).

While it is generally accepted that propofol is addictive, the mechanism by which it works remains unclear. Recently, it has been proposed that glucocorticoid receptor (GR) signaling may be involved in drug addictions. For example, adrenalectomy, which depleted endogenous glucocorticoid (GC), corticosterone, significantly inhibited the dependence on morphine (Marinelli et al., 1998; 
Deroche-Gamonet et al., 2003), and treatments of rats or mice with corticosterone promoted the seeking behavior of drugs (Piazza et al., 1991). On the contrary, the cocaine seeking behavior was inhibited and the concentration of dopamine was decreased significantly by knocking out the gene of GR in mice or by injecting GR antagonist, respectively (Marinelli et al., 1998; Deroche-Gamonet et al., 2003). Such studies indicated that GR played important roles in regulating the addictive process of abused drugs, such as cocaine and morphine (Wang et al., 2008; Ambroggi et al., 2009).

The mesolimbic dopamine system is the common final pathway of drug reward, which takes place mostly in the nucleus accumbens (NAc), an important region in the brain (Bolaños and Nestler, 2004). Multiple drugs implement the reward effects by increasing the concentration of dopamine in the NAc (Koob 1999). GC was reported to be involved in regulating dopamine release and dopamine receptor expression in the NAc (Barrot et al., 2000; Stonehouse et al., 2003). Studies from our group and others have indicated that propofol notably increases the dopamine concentration in the NAc (Pain et al., 2002), which may mediate propofol reward by activating dopamine D1 receptors (Lian et al., 2013). Based on these observations, we hypothesized that GC or GR signaling might be involved in the propofol reward by regulating the dopaminergic system.

In the present study, we examined the effects of either activated (dexamethasone a potent GR agonist), or inhibited (RU486, a specific GR antagonist) on the propofol self-administration, and these pre-treatment on either serum corticosterone 
concentration and/or the expression of D1 receptor in the NAc. 


\section{Experimental Procedures}

\section{Animals}

Adult male Sprague-Dawley rats, weighing 250-300 g, were purchased from the Experimental Animal Center of Wenzhou Medical University. All experiments and procedures were approved by the Animal Care and Use Committee of Wenzhou Medical University, and all operations were performed under anesthesia with sodium pentobarbital, and efforts were made to minimize the number of animals used and their suffering. Animals were housed in individual cage under a $12 \mathrm{~h} / 12 \mathrm{~h}$ light-dark cycle at $22-24{ }^{\circ} \mathrm{C}$, receiving free access to food and water. After the chronically indwelling intravenous catheters were successfully implanted, the rats were randomly assigned into the control and treated groups, and at the end of the experiments, the rats were killed under deep anesthesia with sodium pentobarbital for further analysis.

\section{Drugs}

Propofol, obtained from Astrazeneca (10mg/ml, Diprivan, Italy), was prepared fresh daily during training period. Based on a previous study, a single dosage of propofol (1.7 mg/kg/injection) was used daily for rat self-administration behavior training (McAulliffe et al., 2006). Other agents, including dexamethasone, RU486, spironolactone, and aldosterone were purchased from Sigma Chemical Co. (Sigma, USA), and these agents were dissolved in $50 \%$ ethanol.

\section{Apparatus}

The experiments were done with custom-made operant boxes, sized $30 \mathrm{~cm} \times 30$ 
$\mathrm{cm} \times 30 \mathrm{~cm}$, with the hemline $5 \mathrm{~cm}$ from floor, as being described in our previous studies (Lian et al., 2013; Yang et al., 2011). The reward (self-administration) behavior training was done by a single dosage of propofol daily through jugular injection with a 5-ml syringe attached to a syringe pump at the speed of $1.2 \mathrm{ml} / \mathrm{min}$. In the food-maintained training, sucrose particles were used. The fixed ratio 1 (FR1) training schedule was selected for both trainings. The locomotor activity was tested in a specific motor monitoring device (Panlab, Barcelone Spain) to evaluate the general locomotor activity versus specific addictive property. The experiment procedures were recorded automatically by an IBM-compatible personal computer with a MED Associates interface, which runs self-programmed software written in Borland Delpi 6.0 .

\section{Surgery}

Surgical implantation of intravenous catheters was performed using a previously described method (Zhou et al., 2007). Briefly, under sodium pentobarbital anesthesia, the rats were implanted with chronically indwelling intravenous catheters, which were flushed daily with $0.2 \mathrm{ml}$ saline-heparin solution to maintain the patency of the catheters. After surgical procedure, the rats were treated with penicillin B once every day through the implanted catheter during the recovery period for at least 7 days to prevent infection.

\section{Propofol self-administration training}

Rats were trained for self-administering drugs as previously described (Zhou et al., 2007). During a continuous 14 day period, a 3-hour training session was done 
daily. Rats were moved from their home cages to the operant chambers and then attached the catheter connectors to the infusion line. Each session started with the illumination of the green light inside the active nose-poke hole. The rats received a single propofol infusion of $1.7 \mathrm{mg} / \mathrm{kg}$ following poking the active nose-poke under the schedule of FR1. Each infusion was paired with a 5-s illumination of the house light and the noise from the infusion pump. At the meantime, a time-out period was imposed for 30s, during which further poking produced no programmed consequences but recorded by the computer automatically. Illumination of the green light in the active nose-poke signaled the end of the time-out period, which responds in the inactive nose-poke produced no programmed consequence. All active nose-poke, inactive nose-poke and the number of propofol injections were recorded by the computer, and the sessions ended after 3 hours or reaching 100 propofol injections. One hour prior to the session on day 15 , the trained rats were intraperitoneally injected with vehicle, dexamethasone $(10,30$, or $100 \mu \mathrm{g} / \mathrm{kg})$, RU486 $(10,20$, or 40 $\mathrm{mg} / \mathrm{kg})$, spironolactone $(10,20$, or $40 \mathrm{mg} / \mathrm{kg})$, or dexamethasone $(100 \mu \mathrm{g} / \mathrm{kg})$ combined with aldosterone $(10,30$, or $100 \mu \mathrm{g} / \mathrm{kg})$.

\section{Sucrose self-administration training}

The rats were trained to nose-poke for sucrose pellets under FR1 schedule of reinforcement of a daily 0.5 -hour session for successive 7 days. The paradigm for sucrose self-administration was similar to that of propofol, except that the reward was a $45 \mathrm{mg}$ sucrose pellet (Dustless precision pellets, Bio-Serv, NJ) delivered via a special cup. During the training period, each active nose-poke resulted in a sucrose 
pellet as the reward, but inactive nose-poke resulted in no programmed consequence. All active nose-poke, inactive nose-poke, and the number of sucrose pellets earned were recorded by the computer. One hour prior to the session on day 8 , the trained rats received intraperitoneally either vehicle or a dose of dexamethasone $(10,30$, or 100 $\mu \mathrm{g} / \mathrm{kg})$.

\section{Locomotor activity test}

To further assess the possibility of nonspecific effects of dexamethasone and RU486 on general activity, we examined the effect of intraperitoneal injection of either dexamethasone or RU486 on locomotion in a novel context. One hour prior to the 3-hour test period, the naïve rats $(n=6)$ intraperitoneally received vehicle or dexamethasone $(10,30$, or $100 \mu \mathrm{g} / \mathrm{kg})$. Then, the rats were put into the specific testing box of the monitoring device for a 60-minute acclimation period, and the total distance and time traveled, travelling times, and mean speed were recorded and analyzed by MED Associates SOF-81 Open-field Activity Software.

\section{Western blot analysis}

The NAc of each rat received dexamethasone was removed immediately after completion of propofol self-administration test on day $15(\mathrm{n}=4)$. After deep anesthetization with sodium pentobarbital, each rat was euthanized by decapitation. Brain was quickly removed and placed on ice, and the NAc was dissected out of the brain slices with a rat brain atlas as reference (Paxinos $G$ and Watson C, 2007). Two coronal cuts were made at right angles to the axis of the brain, and the first cut was made $1 \mathrm{~mm}$ anterior to the optic chiasma, the second cut was $1.5 \mathrm{~mm}$ anterior to the 
first cut. The dissected NAc was frozen in liquid nitrogen immediately, and then stored at $-80{ }^{\circ} \mathrm{C}$ for future analysis (Lakehayli $\mathrm{S}$ et al., 2015). Total protein was extracted and the protein concentration of each sample was measured with BCA protein assay kit (Beyotime, China). After being denatured at $100{ }^{\circ} \mathrm{C}$ for $10 \mathrm{~min}$, total proteins $(40 \mu \mathrm{g})$ were loaded on SDS-PAGE gels and separated electrophoretically, followed by transferring the proteins onto PVDF membranes. The no-specific bindings were blocked with 5\% skim milk (Merck) for 2 hours in room temperature and then followed by incubation the membrane in primary D1 antibody (rabbit, 1:1000, Abcam, USA) overnight at $4{ }^{\circ} \mathrm{C}$. The membranes were then incubated in secondary antibody (goat anti-rabbit, 1:5000, Bioworld, China) diluted in TBST for 2 hours in room temperature. Glyceraldehyde-3-phosphate dehydrogenase (GAPDH) was used as the internal control. Finally, the antibodies were visualized with ECL solution (GE Healthcare, USA), and photomicrographs were taken on Image Quant LAS 4000 mini (GE Healthcare, USA). Integral optical density was quantified using the machine software.

\section{Plasma corticosterone concentrations in naïve and propofol self-administrated rats treated with dexamethasone}

After completion of the last training session on day 15, in order to evaluate whether propofol self-administration affects the corticosterone response of animals to dexamethasone, a group of naïve rats with similar treatments $(0,10,30$ or $100 \mu \mathrm{g} / \mathrm{kg}$ dexamethasone) were induced as controls. After anesthetized with sodium pentobarbital, the rats were terminated, and blood was collected into preheparinized 
tubes immediately, and placed on ice. Then, the blood was centrifuged to allow separation of plasma, which was collected and frozen at $-80{ }^{\circ} \mathrm{C}$ until use for further corticosterone determination $(\mathrm{n}=4)$ by an ELISA kit (Corticosterone ELISA kit, Abcam, USA). All steps were performed according to the manufacture's introductions.

\section{Specific experiments}

\section{Experiment 1}

Rats received a 14-day training of propofol self-administration with dose of 1.7 $\mathrm{mg} / \mathrm{kg} /$ infusion were randomly assigned to one of groups and injected intraperitoneally with vehicle, or one dose of dexamethasone $(10,30$, or $100 \mu \mathrm{g} / \mathrm{kg}$; $\mathrm{n}$ $=10$ ) one hour prior to testing on day 15 .

\section{Experiment 2}

The rats trained for propofol self-administration for 14 days were randomly assigned to the groups of vehicle or RU486 $(10,20$ or $40 \mathrm{mg} / \mathrm{kg}$; $\mathrm{n}=7)$ one hour prior to the testing on day 15 .

\section{Experiment 3}

To evaluate the possible impact of mineralocorticoid on the propofol self-administration in rats, we randomly assigned the rats to one of groups of vehicle, spironolactone $(10,20$, or $40 \mathrm{mg} / \mathrm{kg} ; \mathrm{n}=8)$, or dexamethasone $(100 \mu \mathrm{g} / \mathrm{kg})$ combined with aldosterone $(10,30$, or $100 \mu \mathrm{g} / \mathrm{kg} ; \mathrm{n}=8)$, respectively.

\section{Statistical Analysis}

Data are presented as mean \pm standard deviation. We have tested the normal 
distribution, the data of D1 receptor expression between the addiction and naïve groups were analyzed with student test. The data of plasma corticosterone concentrations, the western blot of D1 receptor expression, and the number of responses in active, infusions and inactive responses in food-maintained behavior test groups that were treated with RU486, the activity time and activity times in the locomotor activity test groups that were treated with dexamethasone, and the data in the locomotor activity groups that were treated with RU486, excluding the data of path length, were analyzed by one-way analysis of variance (ANOVA). The Dunett's post hoc test was used for multiple comparisons with the control group if the significance was detected by ANOVA. Because of other data did not distribute normally, and were analyzed with the Kruskal-Wallis test, a non-parametric analysis. Statistical calculations were performed with SPSS 17.0, and $\mathrm{p}<0.05$ was defined to be significant. 


\section{Results}

Both systemic pretreatment with dexamethasone and RU486 attenuated propofol self-administration in rats

The rats were trained to self-administer propofol for 14 days. By the late sessions of the training period, the animals developed reliable propofol self-administration indicated by an increase in active responses and infusions, and a decrease in inactive responses. On day 15, rats were pretreated with either vehicle (control), dexamethasone $(10-100 \mu \mathrm{g} / \mathrm{kg})$ or RU486 $(10-40 \mathrm{mg} / \mathrm{kg})$, before the scheduled self-administration test. Dexamethasone, at the highest dose tested $(100 \mu \mathrm{g} / \mathrm{kg})$, inhibited the number of active nose-poke responses (Fig.1A, $p=0.047$ ) and infusions (Fig.1A, $p=0.008)$, compared to the control group $(\mathrm{p}=0.039)$. Similarly, RU486 also inhibited the number of active responses (Fig.1B, p = 0.0001) and infusions (Fig.1B, $\mathrm{p}=0.0001$ ), though at much lower concentrations (down to $10 \mathrm{mg} / \mathrm{kg}$ ). The inhibitory effects of RU486 are dose-dependent. No significant difference in the number of inactive responses was noticed among groups pretreated with either dexamethasone (p $=0.569)$ or RU486 $(\mathrm{p}=0.708)$.

Systemic pretreatment with spironolactone or dexamethasone combined with aldosterone did not alter the propofol self-administrations

Different from GR drugs, MR ligands did not affect the propofol self-administrations significantly. Administration of spironolactone, an antagonist of MR, did not affect the number of active nose-poke responses (Fig.2A, $\mathrm{p}=0.294, \mathrm{n}=$ $8)$, infusions $(\mathrm{p}=0.428)$ or inactive nose-poke responses $(\mathrm{p}=0.889)$ among all 
treated groups compared to the control group. Furthermore, administration of different doses of aldosterone, an MR agonist, did not rescue/reverse the effects of dexamethasone $(100 \mu \mathrm{g} / \mathrm{kg})$ on the numbers of active responses (Fig.2B, $\mathrm{p}=0.651, \mathrm{n}$ $=8)$, infusions $(\mathrm{p}=0.681)$ or inactive responses at all doses $(\mathrm{p}=0.436)$ compared with the $100 \mu \mathrm{g} / \mathrm{kg}$ dexamethasone control group.

\section{Different effects of systemic pretreatment with dexamethasone and RU486}

At the completion of 14-day propofol self-administration training, the rats were sacrificed immediately for examining the expression of D1 receptor. With ANOVA analysis, we found that systematically injected dexamethasone dose-dependently decreased the expression of D1 receptor in the NAc (Fig.3A, p = 0.004, $n=4$ ), and post tests indicated that the effects were significant cross all doses, compared to the control group. Similarly, RU486 also dose-dependently decreased the expression level of D1 receptor in the NAc at all doses tested (Fig.3B, $p=0.0001, n=4)$. Interestingly, systematically injecting of dexamethasone to the naïve rats failed to affect the expression levels of D1 receptor in the NAc (Fig.3C, p = 0.477, $n=4)$. Furthermore, the D1 receptor expression level in propofol self-administrated control rats was higher than that of the naïve control in the NAc (Fig.3D, p = 0.001, n=4), but not that in the ventral tegmental area $(\mathrm{p}=0.230)$.

The impact of systemic injection of dexamethasone on the plasma corticosterone levels

Blood was collected from rats sacrificed under deep anesthesia for plasma corticosterone detection. The concentrations of plasma corticosterone were decreased, 
dose-dependently, by dexamethasone in both naïve (Fig.4A, p=0.000, n = 4) and propofol self-administrated rats (Fig.4B, $\mathrm{p}=0.0001, \mathrm{n}=4$ ). However, plasma corticosterone levels in propofol self-administrated rats pretreated with vehicle (the control group) were significantly higher than those of the naïve rats pretreated with vehicle (the normal group) $(\mathrm{p}=0.0001)$.

Neither systemic injection of dexamethasone nor RU486 affected food-maintained behavior or locomotor activity

No apparent effects of systematic injection of dexamethasone or RU486 on the number of active nose-poke responses (Fig.5 p = 0.396, $p=0.986, \mathrm{n}=8$ ), the number of sucrose pellets $(\mathrm{p}=0.456, \mathrm{p}=0.926)$ or the number of inactive nose-poke responses $(\mathrm{p}=0.509, \mathrm{p}=0.978)$ were found at the doses adopted in propofol self-administration testing. Also, neither systemic injection of dexamethasone nor RU486 treatment altered the total distance traveled (Fig.6,7 $\mathrm{p}=0.502, \mathrm{p}=0.338, \mathrm{n}=$ $6)$, total travelling time $(\mathrm{p}=0.558, \mathrm{p}=0.715)$, travelling times $(\mathrm{p}=0.382, \mathrm{p}=0.623)$ or mean speed in rats $(\mathrm{p}=0.569, \mathrm{p}=0.612)$. 


\section{Discussions}

The present study found that both GR agonist dexamethasone and antagonist RU486 (i.p.) could significantly affect the propofol self-administration behavior in rats, which may be mediated by either reductions in D1 receptor expression levels in the NAc or decreases in plasma corticosterone concentrations. Besides, we also found that neither spironolactone alone nor aldosterone combined with dexamethasone affected the propofol self-administration behavior in rats. All treatments did not affect food-maintained responses or locomotor activities. Overall, these findings suggest that GR but not MR plays a critical role in mediating propofol self-administration, and this effect may be involved in the expression of dopamine D1 receptors in the NAc.

Previous studies indicated that stress could increase the individual's susceptibility to drug abuse (Sinha 2008). Clinical investigations also found that during the withdrawal period of treating cocaine addictions (Vescovi et al., 1992), the adrenocorticotropic hormone (ACTH) and cortisol levels were increased significantly within 24 hours, and then returned to physiological level, demonstrating that stress affected addiction. The GC effects seem to be mediated mainly by activating the GR. The agonists of GR were demonstrated to promote the dependence on multiple drugs in animal studies, such as cocaine and morphine, and this effect was attenuated by adrenalectomy (Ambroggi et al., 2009). Consistent to this, we demonstrated that RU486, an antagonist of GR, inhibited propofol self-administration in rats. However, very interestingly, we have found that dexamethasone, a GR agonist, also inhibited propofol addictive behaviors. Corticosterone is the main hormone of GC in rats, 
regulated by the hypothalamic-pituitary-adrenal axis (HPA) in vivo. Although dexamethasone is an agonist of GR, both clinical trial and animal researches had found that dexamethasone could significantly reduce plasma cortisol or corticosterone in humans or animals by inhibiting the function of HPA, respectively. A single dose of dexamethasone systematically inhibited corticosterone notably, and multiple injections inhibited the corticosterone to a much lower level (Aouizerate et al., 2006; Reul et al., 1987; Mantsch et al., 1998). One of the explanations to our results could be that the systematically injected dexamethasone may be difficult to pass into the NAc by crossing the blood-brain barrier, but could be much easier to affect secretion of corticosterone. For example, the research by John's group demonstrated that chronically systemic treatment with dexamethasone inhibited the cocaine seeking behavior in rats by decreasing the plasma corticosterone (Mantsch et al., 1998). To further elucidate whether similar mechanism was in play in our study, we have measured the plasma corticosterone concentration and D1 receptor level in the NAc. As expected, we have found systemic dexamethasone attenuated both the plasma corticosterone concentration and D1 receptor level in the NAc. These results suggest that dexamethasone affected propofol self-administrated behavior, probably not by affecting NAc directly, but instead, by indirectly inhibiting the secretion of plasma corticosterone, which further reduced the expression of D1 receptor in the NAc. However, a direct effect of dexamethasone on brain cannot be ruled by our and other studies. Further studies are required for dissecting the direct and indirect effects of dexamethasone on drug addictions. In the future study, conditional GR knockout mice 
in different brain region may solve this problem.

Mesocorticolimbic dopamine system is critical for rewarding. Many addictive drugs, such as cocaine, morphine, heroine, amphetamine, and nicotine are all reported to activate the mesocorticolimbic reward system by elevating dopamine in the NAc. However, whether such a mechanism contributes to the addictive property of propofol remains unknown, and may be different from other drugs of abuse. Two major types of dopamine receptors, D1 receptor and D2 receptor families were related to drug abuse, some studies suggested cocaine and morphine addiction may relate to both dopamine D1 and D2 receptors (Bachtell et al., 2005; Reisi et al., 2014), and our previous study demonstrated that D1, not D2, receptor in the NAc may participate in mediating propofol reward (Lian et al., 2013). GR expresses in multiple regions of brain, including the NAc, hippocampus, amygdala, and cortex, where it plays a critical role in regulating the expression of dopamine receptors. In this study, we found that injecting either dexamethasone or RU486 decreased the expression of D1 receptor in the NAc, with a reduction of plasma corticosterone. The reduced D1 receptor by dexamethasone and RU486 may be not specific to nuclear accumbens. Iasevoli et al. demonstrated that dexamethasone reduced mRNA level of D1 receptors in the cortex and striatum (Iasevoli et al., 2013). The expression of D1 receptor in the NAc but not VTA in propofol self-administrated rats increased remarkably compared with naïve rats. At the meantime, we also found that no significance difference of the D1 receptor expression in the NAc in dexamethasone treated naïve rats, indicating the dexamethasone could not affect the D1 receptor expression in these rats, although 
some other studies reported dexamethasone significantly decreased the mRNA level of D1 receptor in the striatum (Iasevoli et al., 2013). Other studies also reported different effects on locomotor activities from RU486 treatment between morphine addicted and naïve rats (Marinelli et al., 1998), however, the mechanisms need further studies.

Endogenous GC (corticosterone in rats) in vivo has the same binding affinity to two different receptors, low-affinity GR that has endogenous GC cortisol or corticosterone and high-affinity mineralocorticoid receptor (MR) that has endogenous mineralocorticoid aldosterone. MR can be activated by a low level of plasma corticosterone while GR can be activated by a high level of this hormone (Joëls et al., 2008). Since dexamethasone may affect the addictive behavior through reducing the plasma corticosterone, here we also examined whether MR agonist and/or antagonist could affect the influence of dexamethasone on propofol self-administrated behavior. The role of MR in drug addiction remains controversial. Some studies reported that MR participated in regulating the cocaine addiction, inhibiting the cocaine seeking behavior and locomotor activity in mice (Fiancette et al., 2010), and aldosterone reversed the inhibition of dexamethasone on cocaine seeking behavior in mice at the dose of $100 \mu \mathrm{g} / \mathrm{kg}$ (Mantsch et al., 1998). However, other studies reported that injecting spironolactone intraperitoneally had no notable effects on DA level in the NAc or locomotor activity in mice (Marinelli et al., 1998). In the present study, we have found that spironolactone, or aldosterone did not affect the propofol self-administration significantly. These results demonstrated that the MR may not 
affect the propofol self-administration in rats significantly in the current conditions, which further indicated the mechanism of propofol was distinct from cocaine. In a recent study, it was also demonstrated that MR blockade did not affect morphine withdrawal (Navarro-Zaragoza et al., 2015) while GR blockade affected the withdrawal-induced ERK and CREB phosphorylation and tyrosine hydroxylase expression level in the nucleus of tractus solitarius. The present results indicate that brain GR is a therapeutic target for propofol addiction.

In conclusion, the present data provides evidence that systemic administration of dexamethasone and RU486 can inhibit the propofol reward by decreasing D1 receptor expression, and the study supports the hypothesis that GR, not MR, may play a role in the propofol self-administration behavior in rats.

\section{Authors Contribution}

LQQ and GRS were responsible for the study concept and design. WBB, LYY, DZL, CZC, ZGL, WSC, LWX contributed to the acquisition of animal data. WBB performed the data analysis and drafted the manuscript. GRS and WBF assisted the interpretation of findings. All authors critically reviewed content and approved final version for publication.

\section{Competing Interests}

The authors declare no conflict of interest. 


\section{Acknowledgements}

The research was supported by the National Science Foundation of China (81271469),

Research Foundation of Doctor Program (20113321110003) to Qingquan Lian, Medicine Health Project of Zhejiang Province, China (2014KYB161) and Scientific Research Foundation of Wenzhou, Zhejiang Province, China (Y20140629). The authors are grateful to Dr. Haolin Chen, Professor of John Hopkins University, for his critical reading and help in language. 


\section{References:}

Ambroggi F, Turiault M, Milet A, Deroche-Gamonet V, Parnaudeau S, Balado E, Barik J, van der Veen R, Maroteaux G, Lemberger T, Schütz G, Lazar M, Marinelli M, Piazza PV, Tronche F (2009) Stress and addiction: glucocorticoid receptor in dopaminoceptive neurons facilitates cocaine seeking. Nat Sci Neurosci 12: 247-249. Aouizerate B, Ho A, Schluger JH, Perret G, Borg L, Le Moal M, Piazza PV, Kreek MJ (2006) Glucocortocoid negative feedback in methadone-maintained former heroin addicts with ongoing cocaine dependence: dose-response to dexamethasone supression. Addict Biol 11: 84-96.

Bolaños CA, Nestler EJ (2004) Neurotrophic mechanisms in drug addiction. Neuromolecular Med 5:69-83.

Barrot M, Marinelli M, Abrous DN, Rougé-Pont F, Le Moal M, Pizza PV (2000) The dopaminergic hyper-responsiveness of the shell of the nucleus accumbens is hormone-dependent. Eur J Neurosci 12:973-979.

Bachtell RK, Whisler K, Karanian D, Self DW (2005) Effects of intra-nucleus accumbens shell administration of dopamine agonists and antagonists on cocaine-taking and cocaine-seeking behaviors in the rats. Psychopharmacology (Berl) $183: 41-53$.

Deroche-Gamonet V, Sillaber I, Aouizerate B, Izawa R, Jaber M, Ghozland S, Kellendonk C, Le Moal M, Spanagel R, Schütz G, Tronche F, Piazza PV (2003) The glucocorticoid receptor as a potential target to reduce cocaine abuse. J Neurosci 23:4785-4790. 
Fiancette JF, Balado E, Piazza PV, Deroche-Gamonet V (2010) Mifepristone and spironolactone differently alter cocaine intravenous self-administration and cocaine-induced locomotion in C57BL/6J mice. Addict Biol 15:81-87.

Iasevoli F, Aloi L, Latte G, Awisati L, Marmo F, Tomasetti C, Buonaguro EF, Simeoli C, Pivonello R, Colao A, de Bartolomeis A (2013) The glucocorticoid analog dexamethasone alters the expression and the distribution of dopamine receptors and enkephalin within cortico-subcortical regions. Curr Mol Pharmacol 6:149-155.

Joëls M, Karst H, DeRijk R, de Kloet ER (2008) The coming out of the brain mineralocorticoid receptor. Trend Neurosci 31:1-7.

Reisi Z, Bani-Ardalan M, Zarepour L, Haghparast A (2014) Involvement of D1/D2 dopamine receptor within the nucleus accumbens and ventral tegmental area in the development of sensitization to antinociceptive effect of morphine. Pharmacol Biochem Behav 118:16-21.

Koob GF (1999) The role of the striatopallidal and extended amygdala systems in drug addiction. Ann N Y Acad Sci 877:445-460.

Lesage MG, Stafford D, Glowa JR (2000) Abuse liability of the anesthetic propofol:self-administration of propofol in rats under fixed-ratio schedules of drug delivery. Psychopharmacology 153:148-154.

Navarro-Zaragoza J, Laorden ML, Milanés MV (2015) Glucocorticoid receptor but not mineralocorticoid receptor mediates the activation of ERK pathway and CREB during morphine withdrawal. Addict Biol doi:10.111/adb.12328.

Lian Q, Wang B, Zhou W, Jin S, Xu L, Huang Q, Lai M, Lu K, Tang L, Zhu H, Lin H, 
Zhang F, Cao H, Li J, Chen JF, Ge RS (2013) Self-administration of propofol is mediated by dopamine D1 receptors in nucleus accumbens in rats. Neuroscience 231:373-383.

Lakehayli S, Said N, Khachibi ME, Ouahli ME, Nadifi S, Hakkou F, Tazi A (2015) Long-term effects of prenatal stress and diazepam on D2 receptor expression in the nucleus accumbens of adult rats. Neurosci Lett 594:133-136.

McAulliffe PF, Gold MS, Bajpai L, Merves ML, Frost-Pineda K, Pomm RM, Goldberger BA, Melker RJ, Cendán JC (2006) Second-hand exposure to aerosolized intravenous anesthetics propofol and fentanyl may cause sensitization and subsequent opiate addiction among anesthesiologists and surgeons. Med Hupotheses 66:874-882. Marinelli M, Aouizerate B, Barrot M, Le Moal M, Piazza PV (1998) Dopamine-dependent responses to morphine depend on glucocrticoid receptors. Proc Natl Acad Sci USA 95:742-747.

Mantsch JR, Saphier D, Goeders NE (1998) Corticosterone facilitates the acquisition of cocaine self-administration in rats: opposite effects of the type II glucocorticoid receptor agonist dexamethasone. J Pharmacol Exp Ther 287:72-80.

Piazza PV, Maccari S, Deminière JM, Le Moal M, Mormède P, Simon H (1991) Corticosterone levels determine individual vulnerability to amphetamine self-administration. Proc Natl Acad Sci USA 88:2088-2092.

Pain L, Gobaille S, Schleef C, Aunis D, Oberling P (2002) In vivo dopamine measurements in the nucleus accumbens after nonanesthetic and anesthetic doses of propofol in rats. Anesth Analg 95:915-919. 
Paxinos G, Watson C (2007) The rat brain in stereotaxic coordinates, sixth edition, New York: Elsevier Academic Press.

Reul JM, van den Bosch FR, de Kloet ER (1987) Relative occupation of type I and type II corticosteroid receptors in rat brain following stress and dexamethasone treatment: functional implication. J Endocrinol 115:459-467.

Stonehouse AH, Adachi M, Walcott EC, Jones FS (2003) Caffeine regulates neuronal expression of the dopamine 2 receptor gene. Mol Pharmacol 64:1463-1473.

Sinha R (2008) Chronic stress, drug use, and vulnerability to addiction, Ann N Y Acad Sci 1141:105-130.

Vescovi PP, Coiro V, Volpi R, Passeri M (1992) Diurnal variations in plasma ACTH, cortisol and beta-endorphin levels in cocaine addicts. Horm Res 37:221-224.

Wischmeyer PE, Johnson BR, Wilson JE, Dingmann C, Bachman HM, Roller E, Tran ZV, Henthorn TK (2007) A survey of propofol abuse in academic anesthesia programs. Anesth Analg 105:1066-1071.

Wang XY, Zhao M, Ghitza UE, Li YQ, Lu L (2008) Stress impairs reconsolidation of drug memory via glucocorticoid receptors in the basolateral amygdala. J Neurosci 28:5602-5610.

Yang B, Wang BF, Lai MJ, Zhang FQ, Yang XW, Zhou WH, Lian QQ (2011) Differential involvement of $\mathrm{GABA}_{\mathrm{A}}$ and $\mathrm{GABA}_{\mathrm{B}}$ receptor in propofol self-administration in rats. Acta Pharmacol Sin 32:1460-1465.

Zhou W, Liu H, Zhang F, Tang S, Zhu H, Lai M, Kalivas PW (2007) Role of acetylcholine transmission in nucleus accumbens and ventral tegmental area in 
heron-seeking induced by conditioned cues. Neuroscience 144:1209-1218. 


\section{Figures and Figure legends}

Figure 1. Effects of dexamethasone and RU486 on propofol induced self-administration under an FR1 training schedule. Following the successive 14-day propofol self-administration training, the rats were treated with vehicle (control), or one dose of dexamethasone $(10,30$, or $100 \mu \mathrm{g} / \mathrm{kg}, \mathrm{n}=10)$, or RU486 $(10,20$, or 40 $\mathrm{mg} / \mathrm{kg}, \mathrm{n}=7$ ), one hour before the testing schedule on day 15 . Both dexamethasone $(\mathrm{A}, \mathrm{p}<0.05$ at $100 \mu \mathrm{g} / \mathrm{kg})$ and RU486 (B, p < 0.01 at all doses) attenuated active nose-poke responses and infusions compared to the control group. No significant difference was found in inactive nose-poke responses among any of the groups $(\mathrm{p}>$ $0.05)$. The data are presented as mean \pm standard deviation.

Figure 2. Effects of MR antagonist and agonist on intravenous propofol self-administration under an FR1 training schedule. After being trained to propofol self-administration for 14 days, the rats were pretreated with vehicle (control), or spironolactone $(\mathrm{A}, 10,20$, or $40 \mathrm{mg} / \mathrm{kg}, \mathrm{n}=8)$, or a combination of dexamethasone (B, $100 \mu \mathrm{g} / \mathrm{kg})$ with one of doses of aldosterone $(10,30$ or $100 \mu \mathrm{g} / \mathrm{kg}, \mathrm{n}=8)$ one hour prior to the testing schedule on day 15 . No significant difference was found on active nose-poke responses, infusions or inactive nose-poke responses among any group ( $\mathrm{p}>$ $0.05)$. The data are presented as mean \pm standard deviation.

Figure 3.The effects of systemic injection of dexamethasone and RU486 on the expression levels of D1 receptor in rats. Both dexamethasone and RU486 
down-regulated the expression levels of D1 receptor in the NAc dose-dependently (A, $\mathrm{B}, \mathrm{p}<0.01, \mathrm{n}=4)$. However, dexamethasone did not affect the $\mathrm{D} 1$ receptor expression in naïve rats (normal) $(\mathrm{C}, \mathrm{p}>0.05, \mathrm{n}=4)$, and D1 receptor expression in propofol self-administrated rats was higher than that in the naïve rat NAc $(D, p<0.01$, $\mathrm{n}=4)$ but not that in the ventral tegmental area (VTA) $(\mathrm{p}>0.05, \mathrm{n}=4)$. The data are presented as mean \pm standard deviation.

Figure 4.The effects of systemic injection of dexamethasone on the concentrations of plasma corticosterone. Dexamethasone (i.p.) reduced the plasma corticosterone levels dose-dependently in both naïve $(\mathrm{A}, \mathrm{p}<0.01, \mathrm{n}=4)$ and propofol self-administrated rats $(B, p<0.01, n=4)$. The data are presented as mean \pm standard deviation.

Figure 5. The effects of dexamethasone and/or RU486 on the food-induced sucrose responses. Both the dexamethasone (A) and RU486 (B) did not alter the active responses, infusions or inactive responses of the food-induced sucrose responses ( $p$ > $0.05, \mathrm{n}=8$ ). The data are presented as mean \pm standard deviation.

Figure 6. The effects of dexamethasone on the locomotor activities. Systemic injection of vehicle, 10,30 and $100 \mu \mathrm{g} / \mathrm{kg}$ dexamethasone did not affect total distance traveled, total travelling time, travelling times or mean speed significantly $(\mathrm{p}>0.05, \mathrm{n}$ $=6$ ). The data are presented as mean \pm standard deviation. 
Figure 7. The effects of RU486 on the locomotor activities. Systemic injection of vehicle, 10, 20 and $40 \mathrm{mg} / \mathrm{kg}$ RU486 did not make significant difference on total distance traveled, total travelling time, travelling times or mean speed significantly $(\mathrm{p}>$ $0.05, \mathrm{n}=6)$. The data are presented as mean \pm standard deviation. 

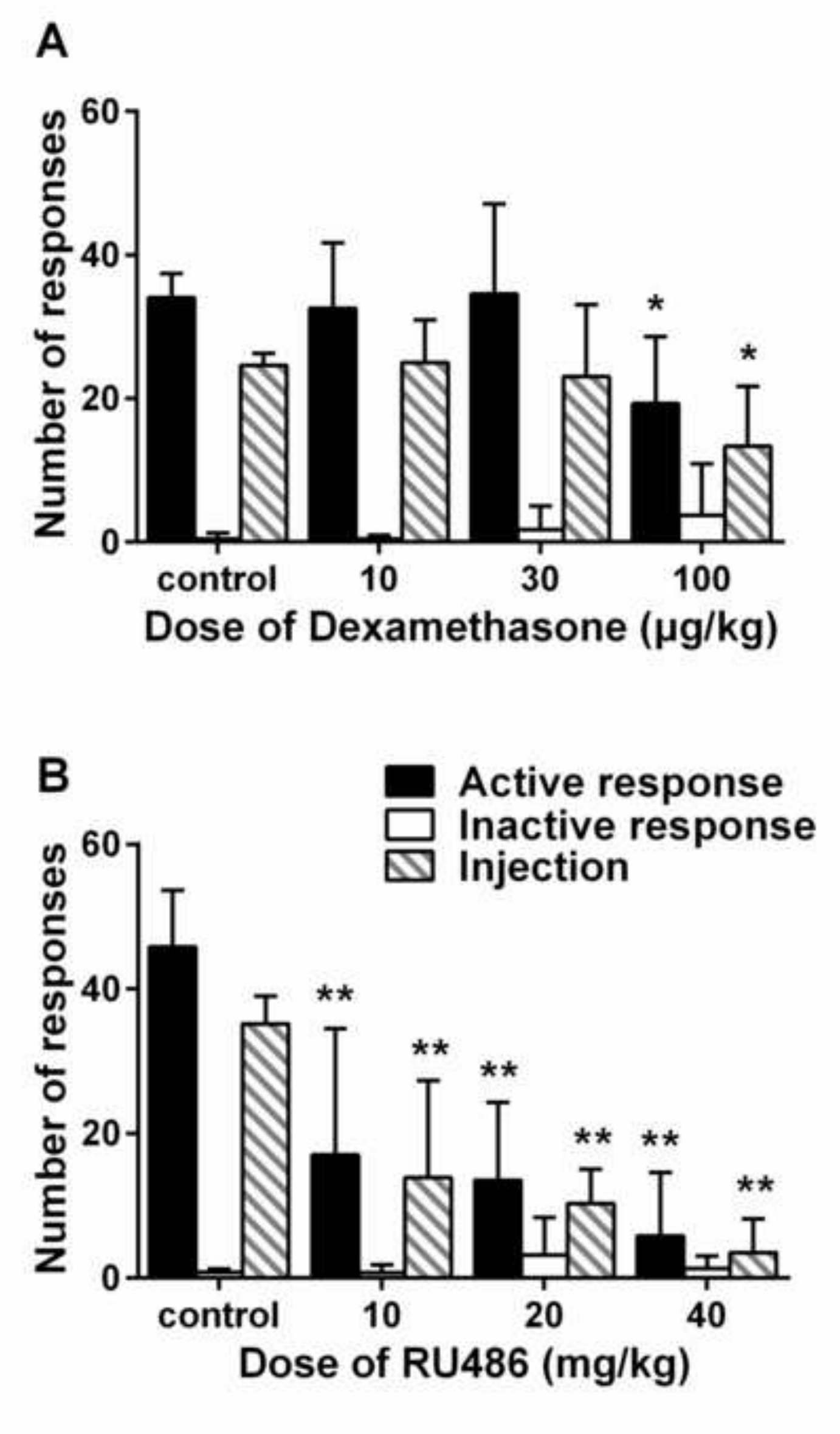

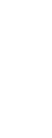

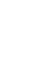

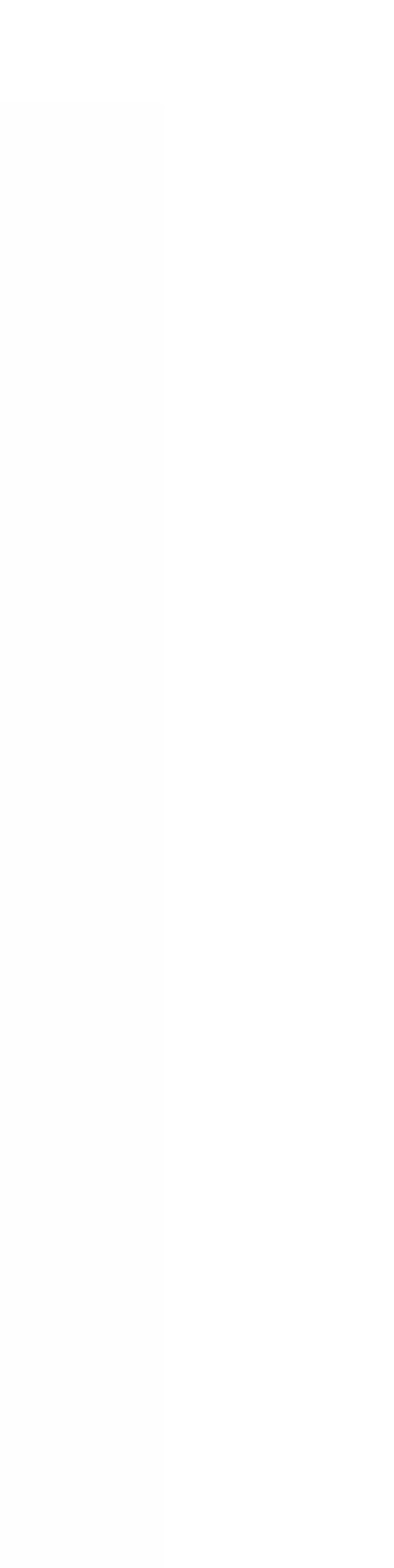




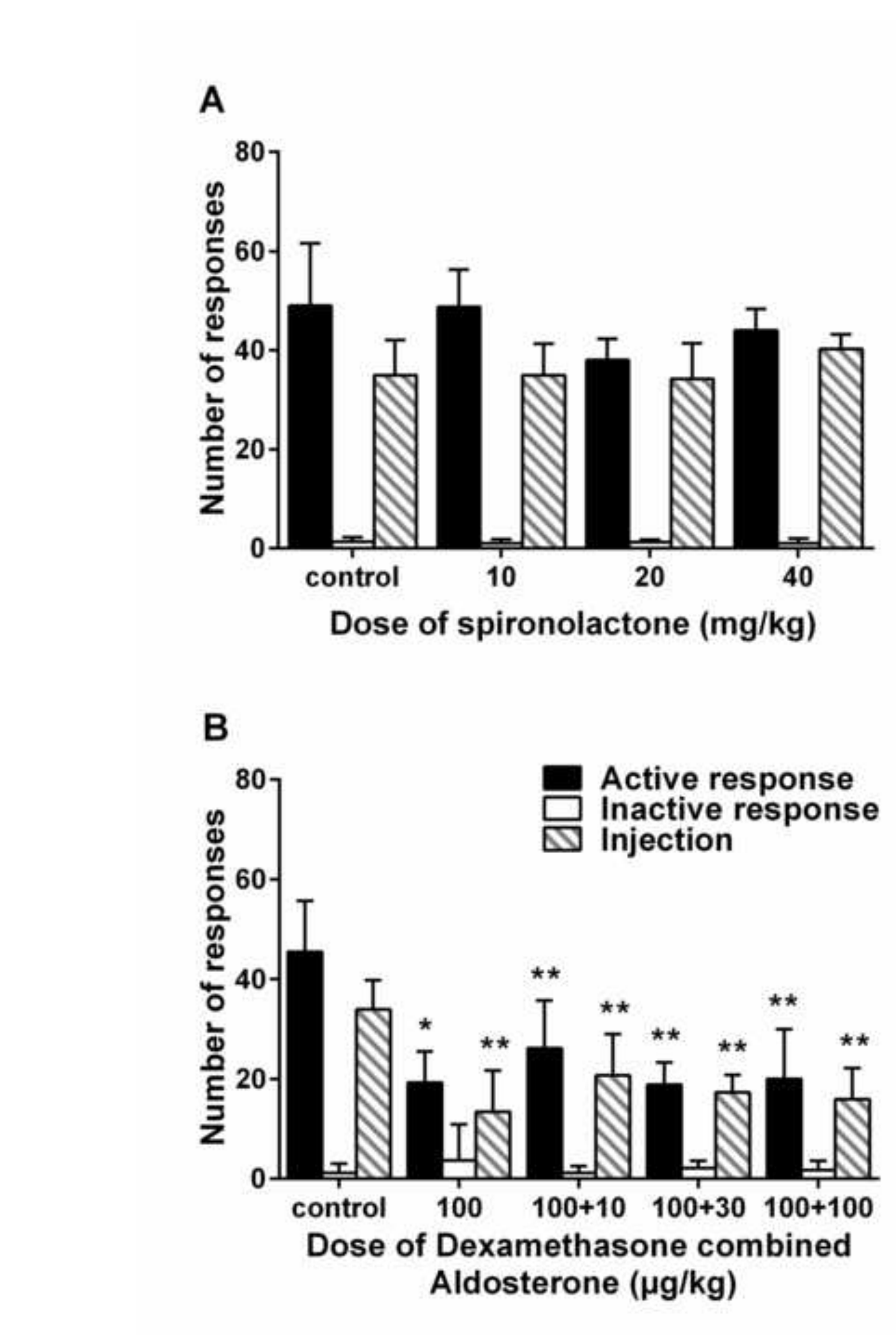

B

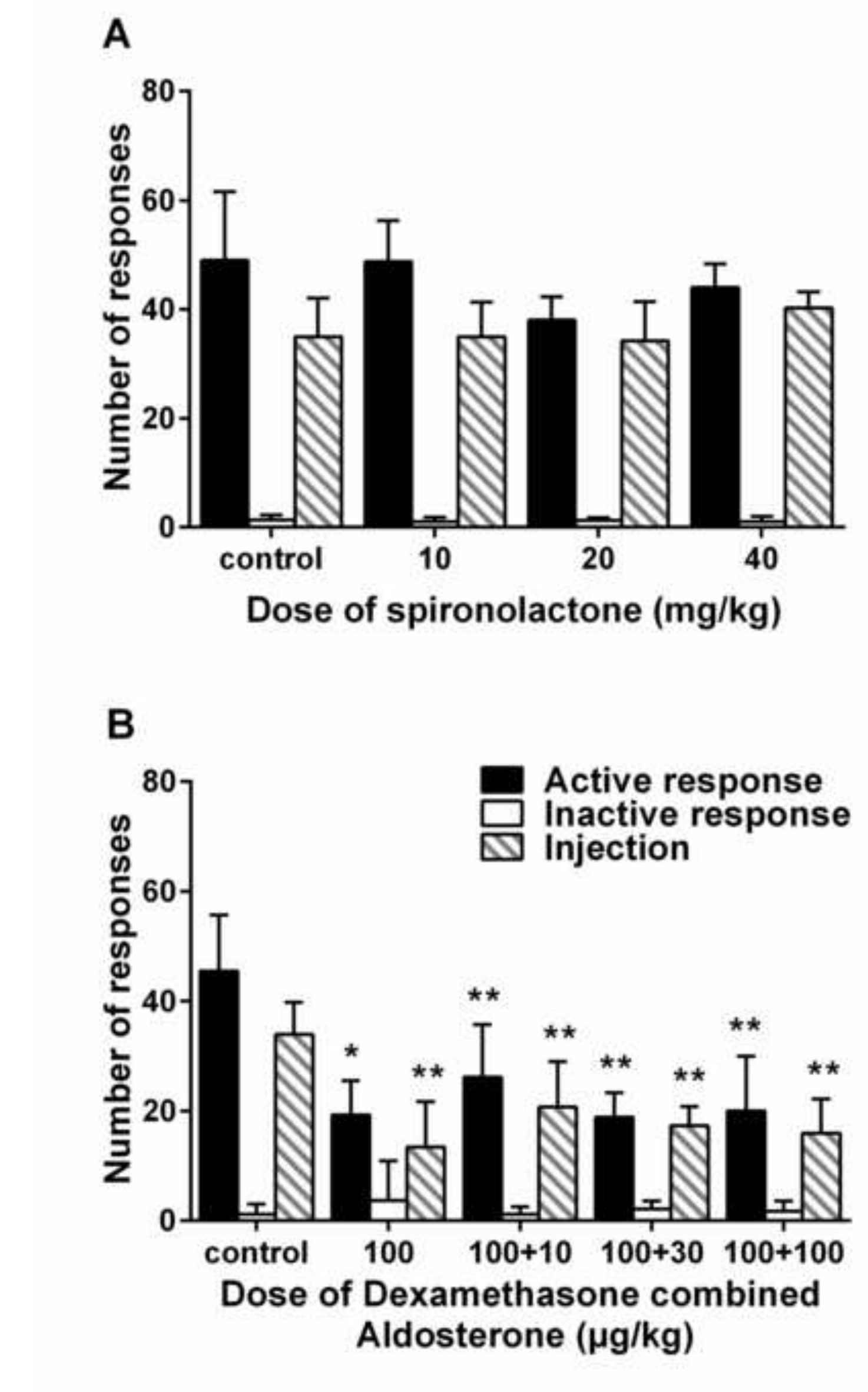

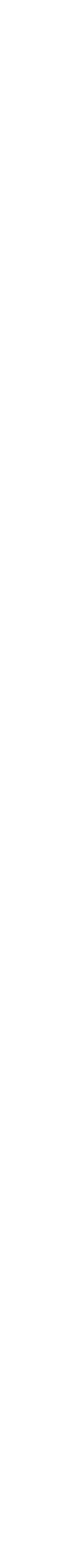

.

3
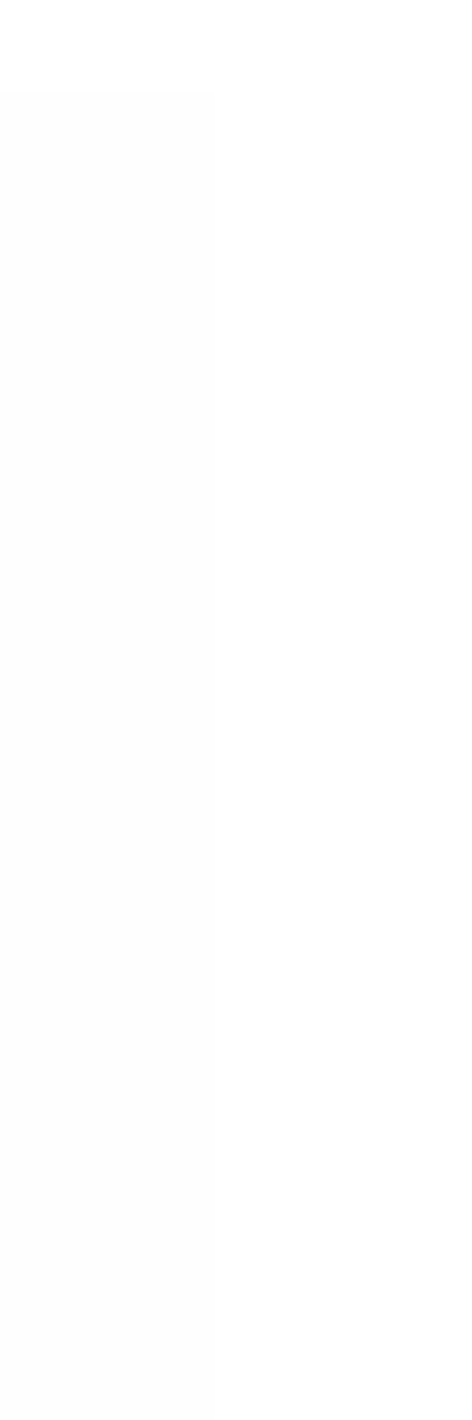

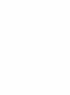


A $D_{1} R \longrightarrow$

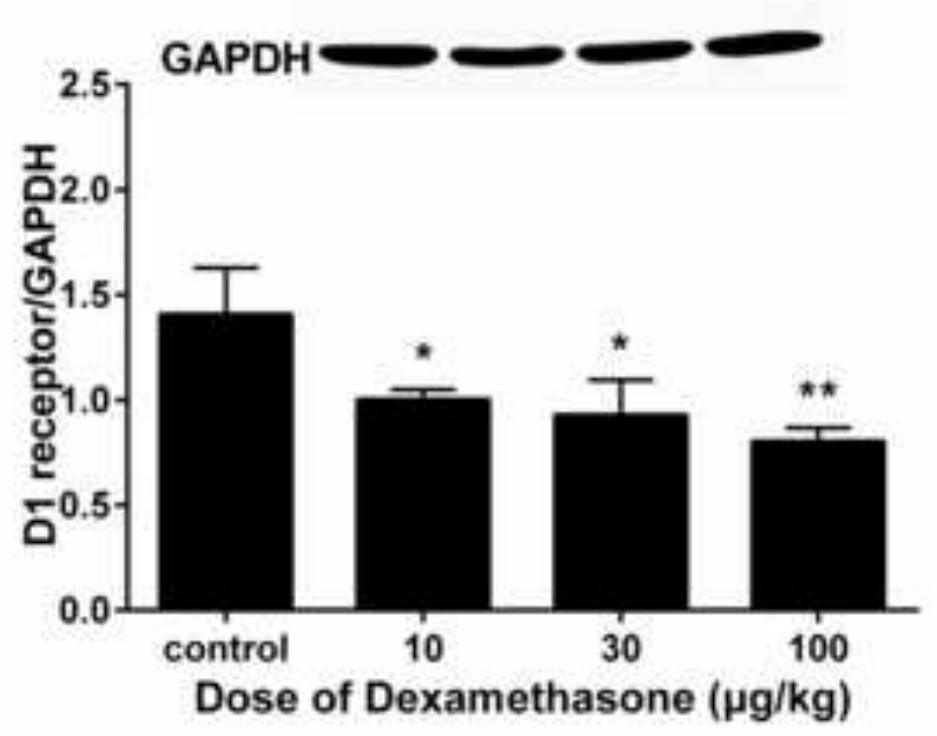

C $\quad D_{1} R$

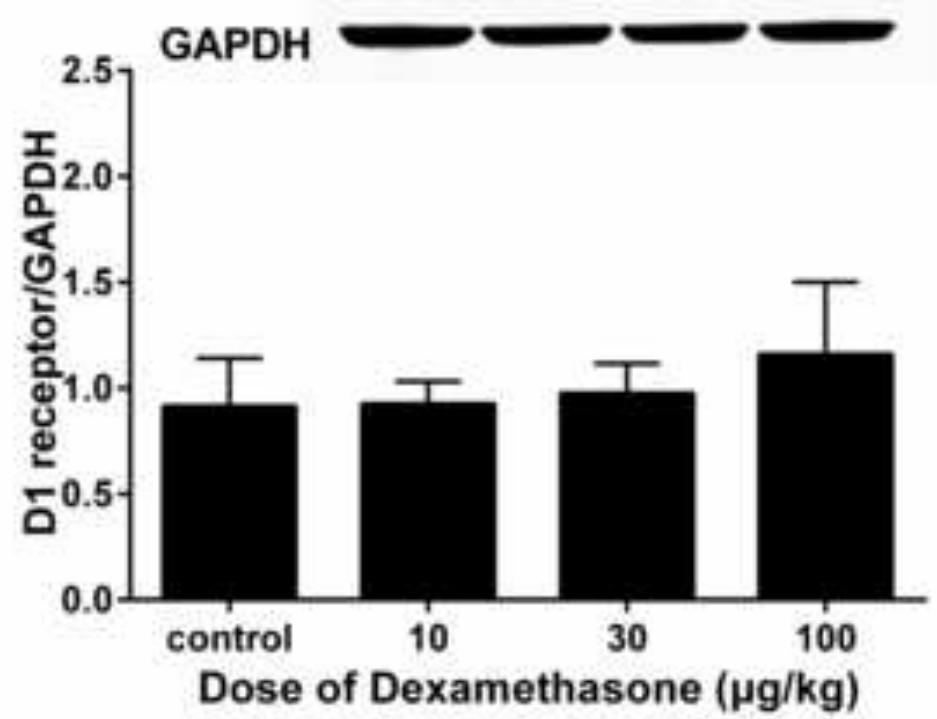

B $\quad D_{1} R$

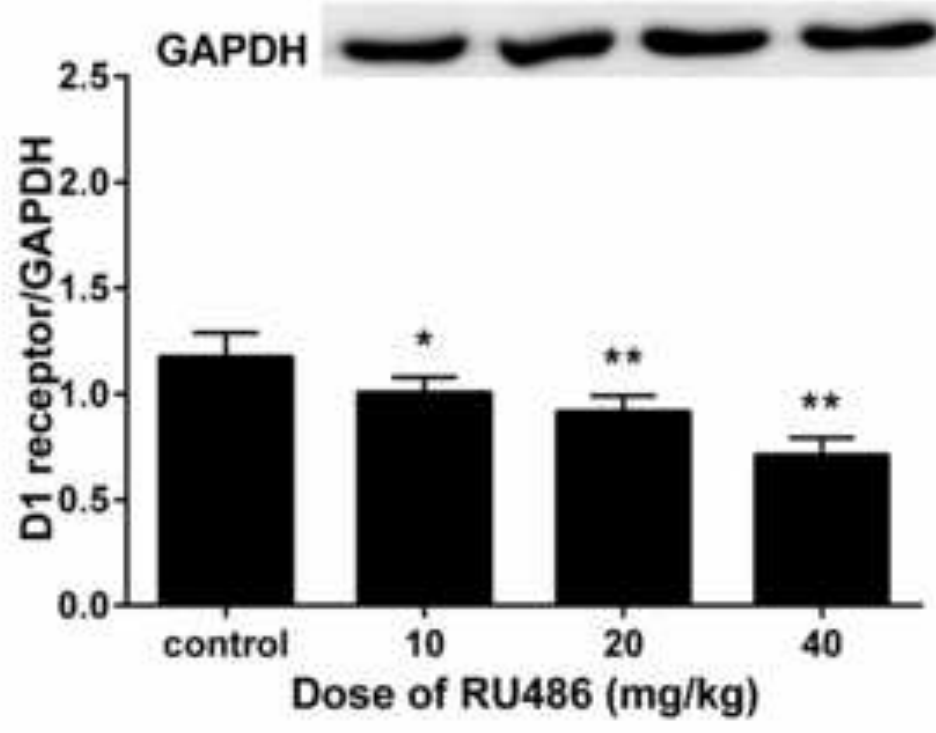

D $\quad D_{1} R$

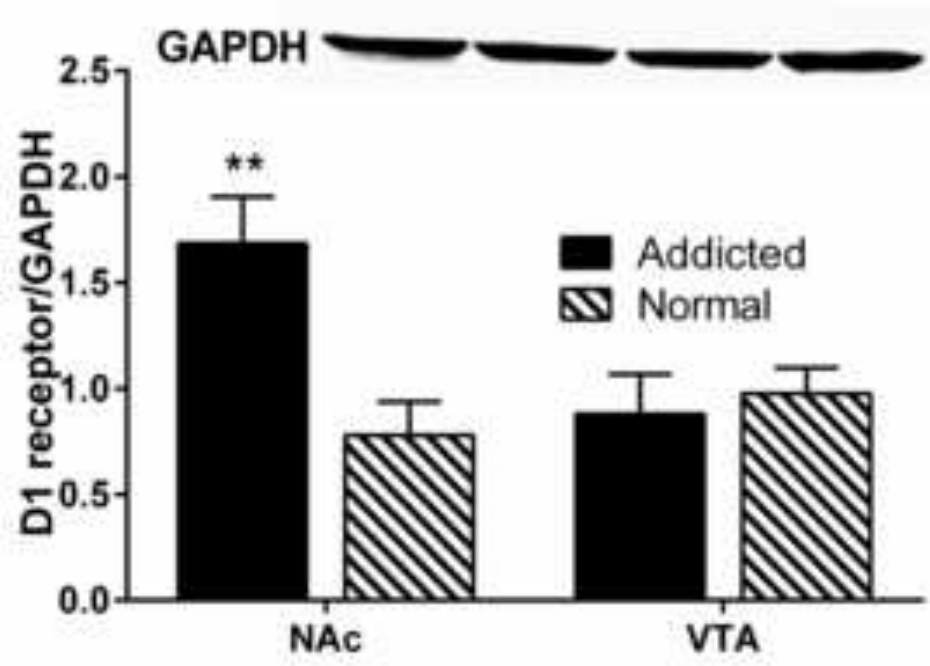



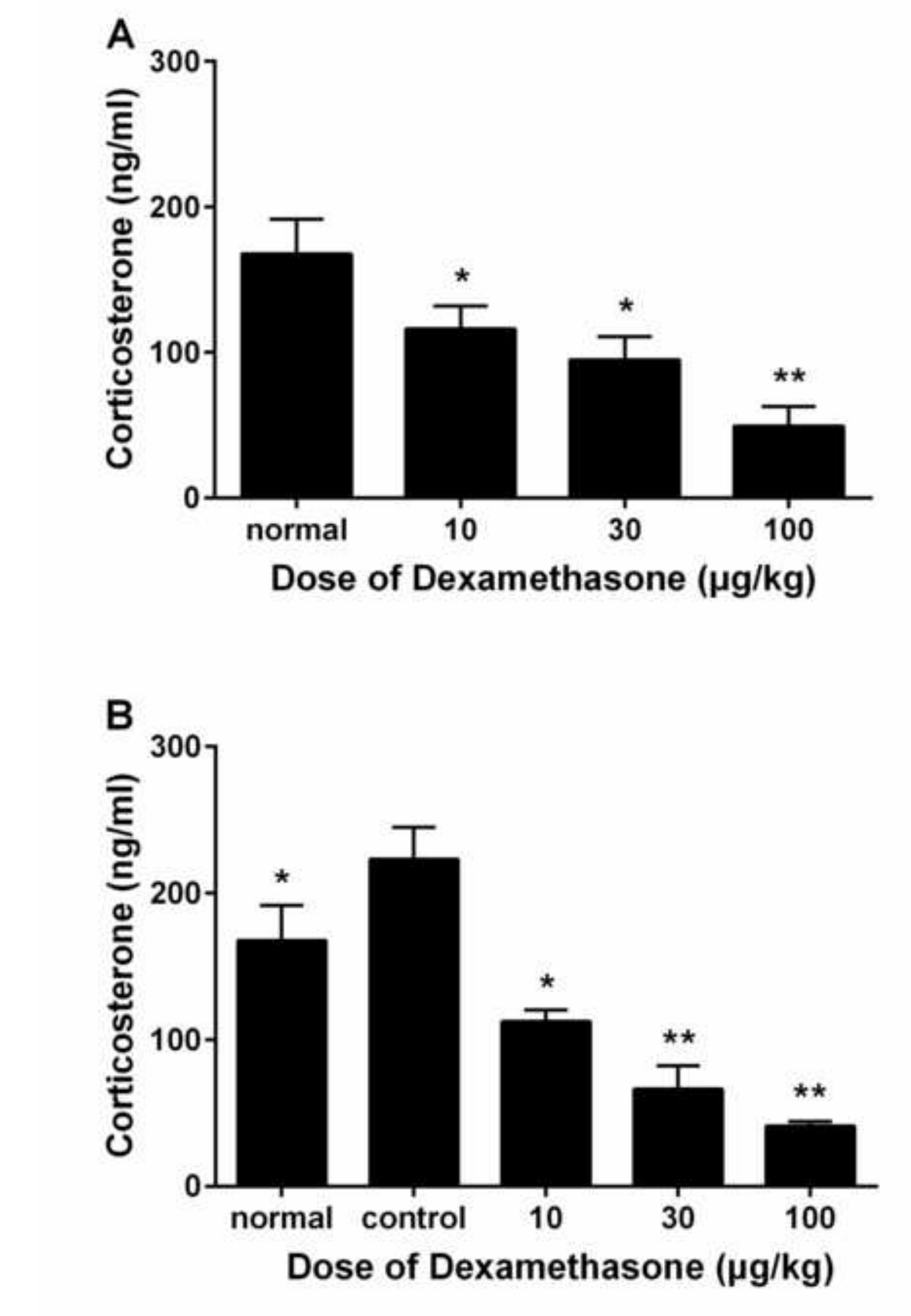

do

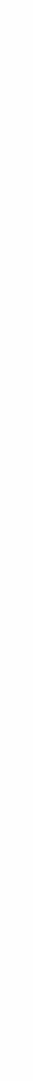

.

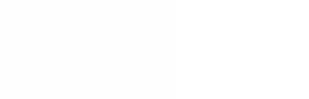
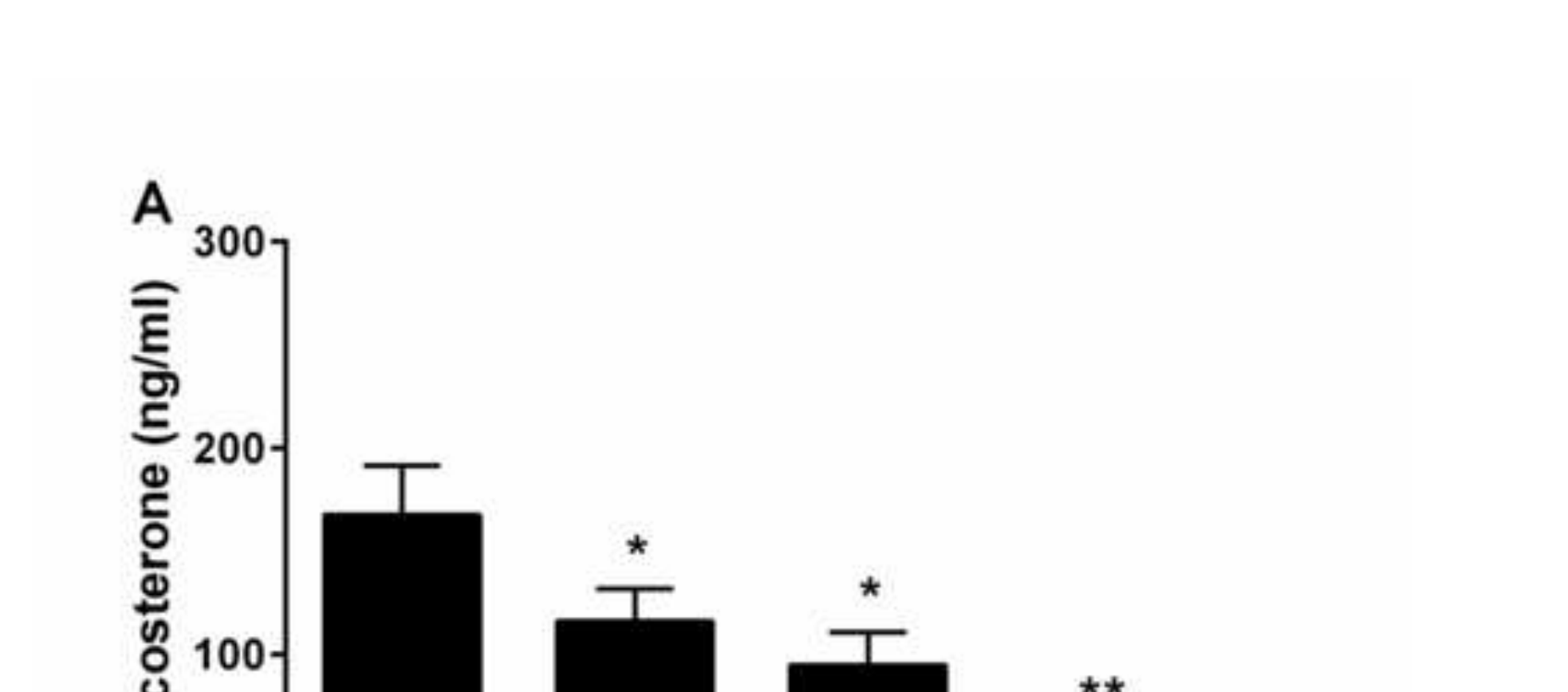

(

.
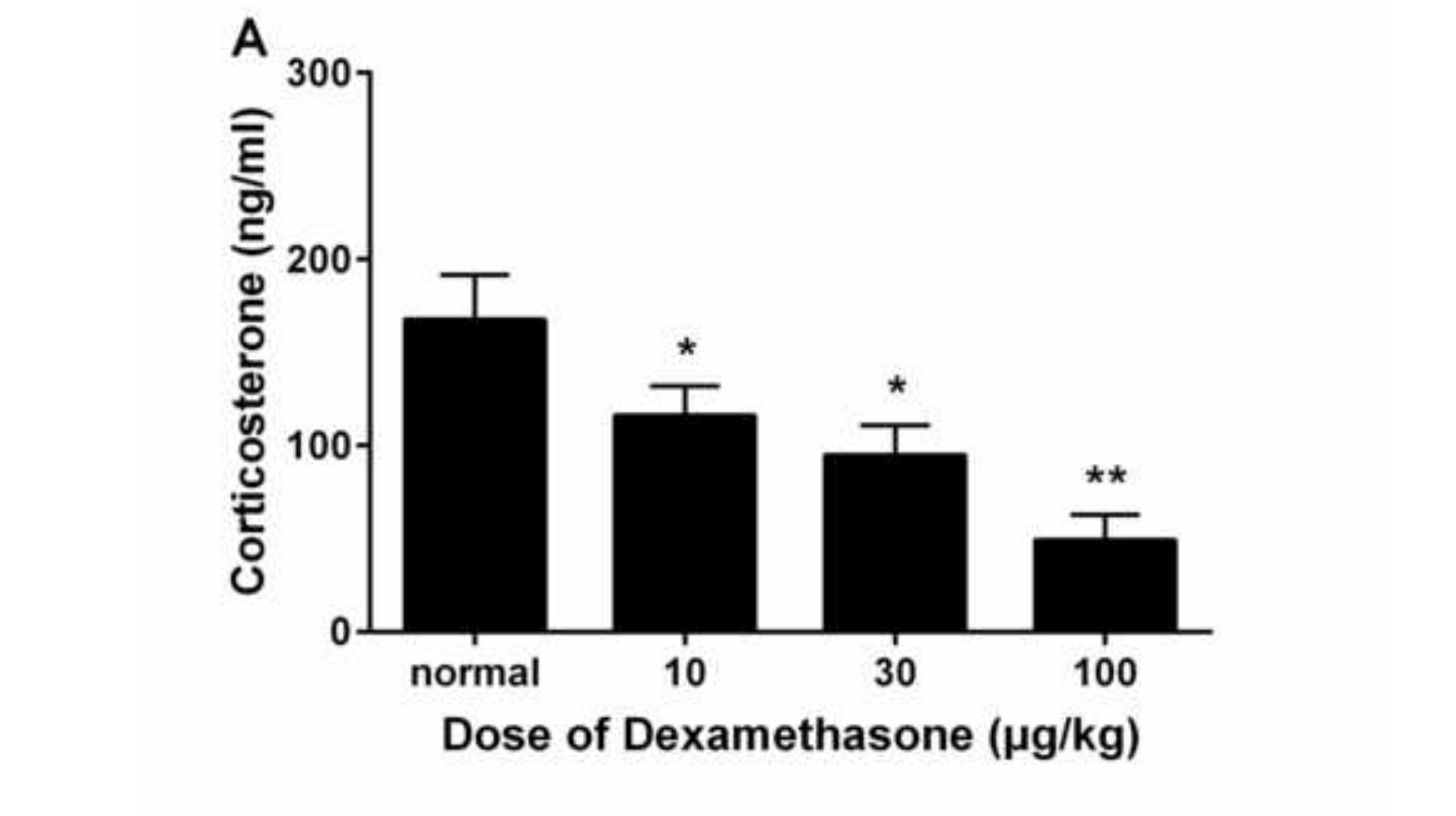

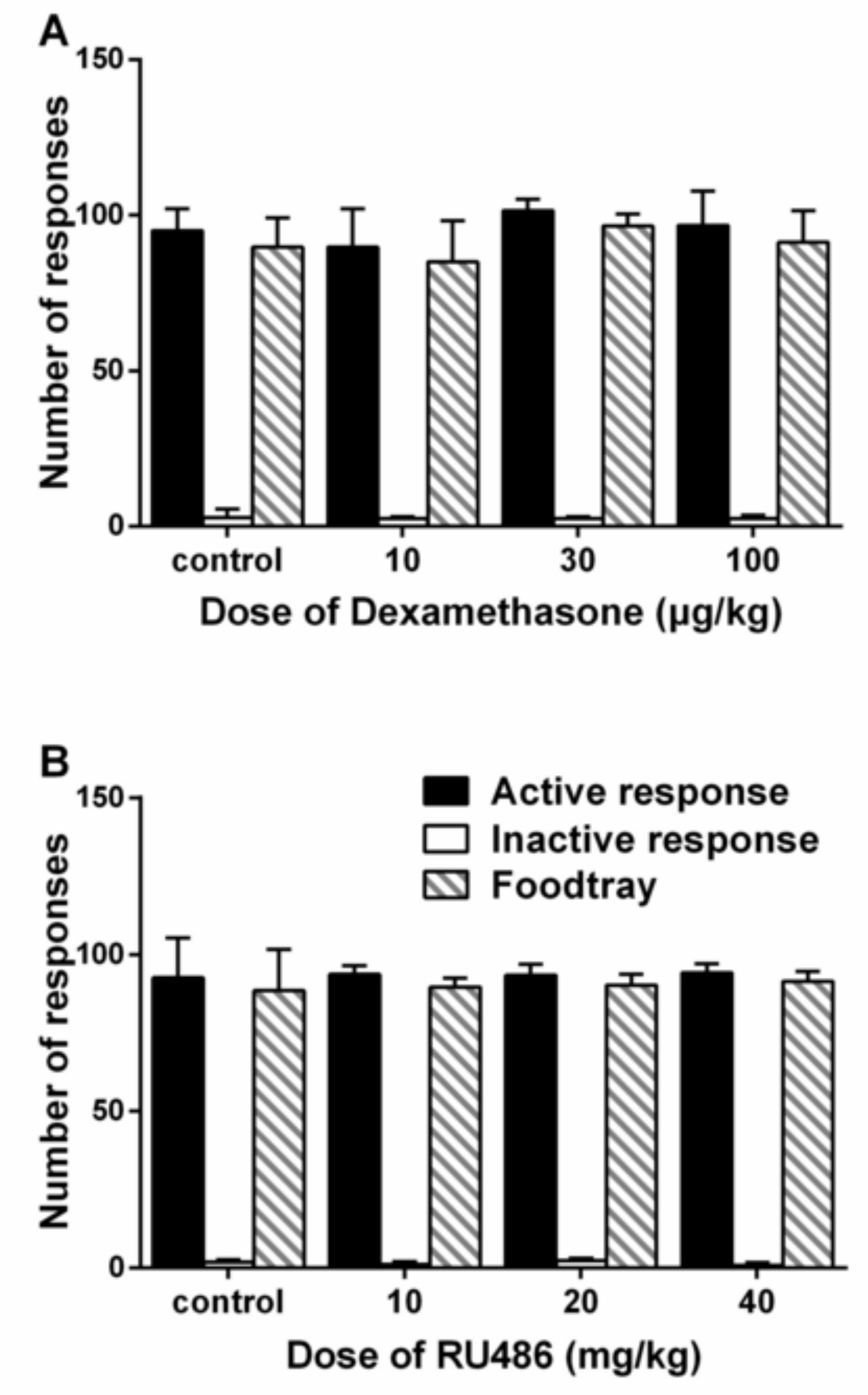
A

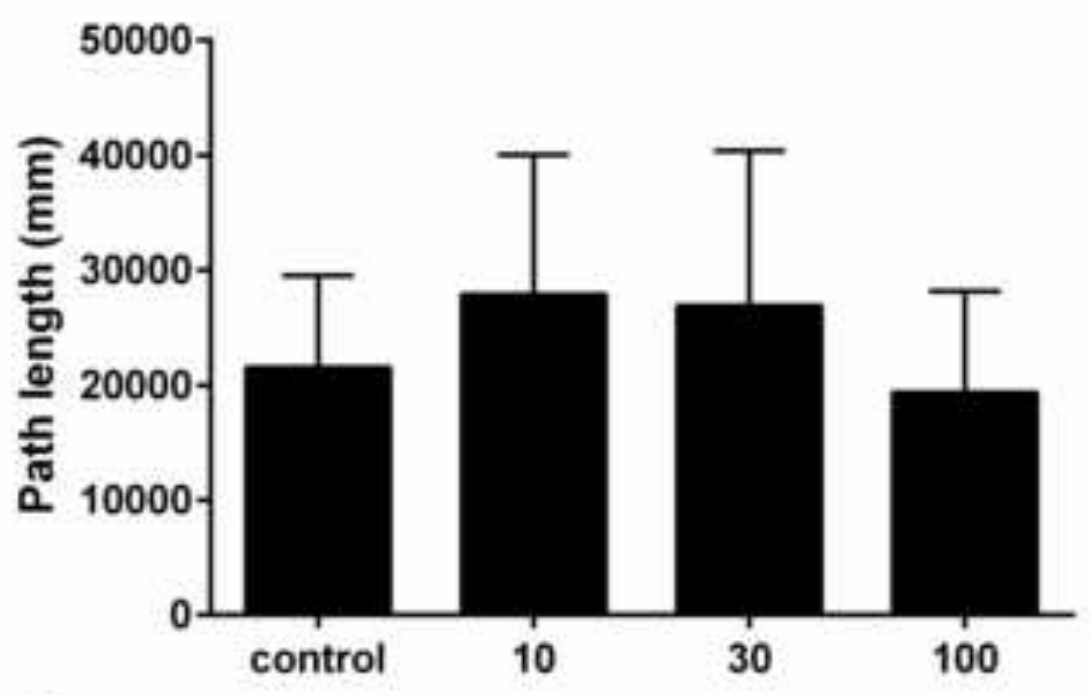

C

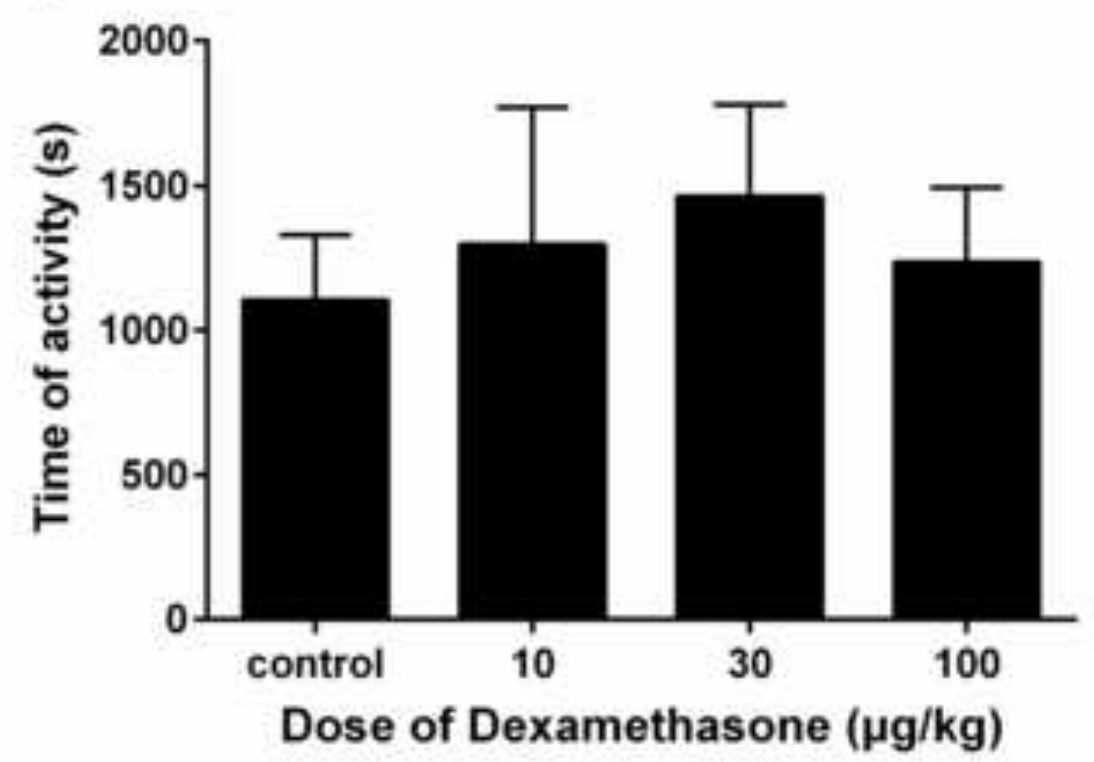

B

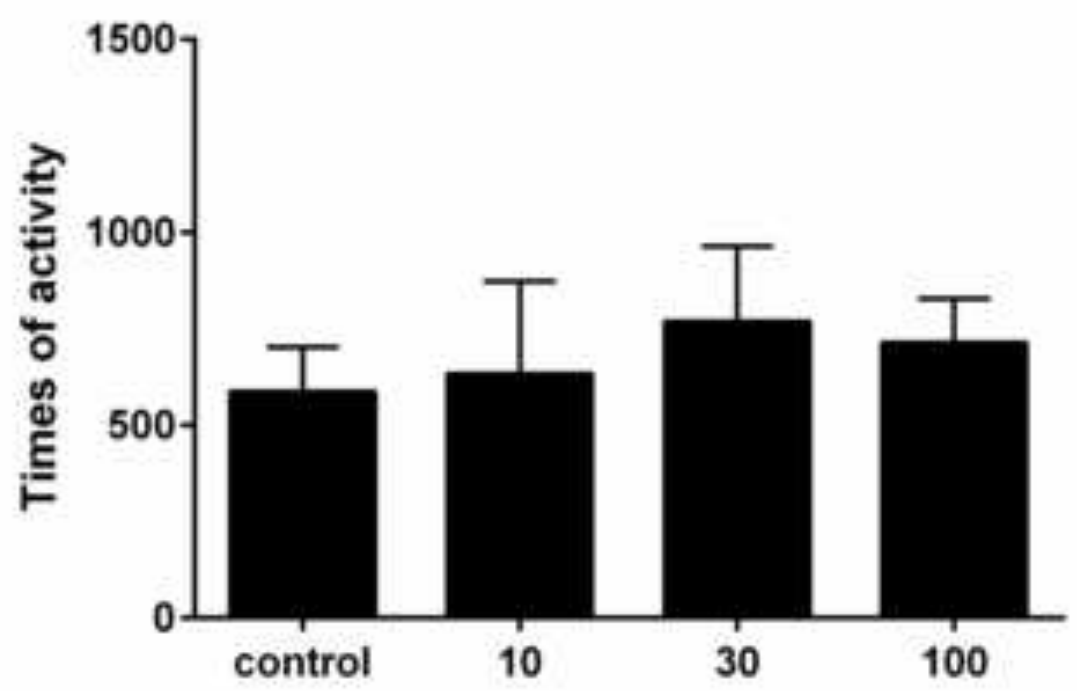

D

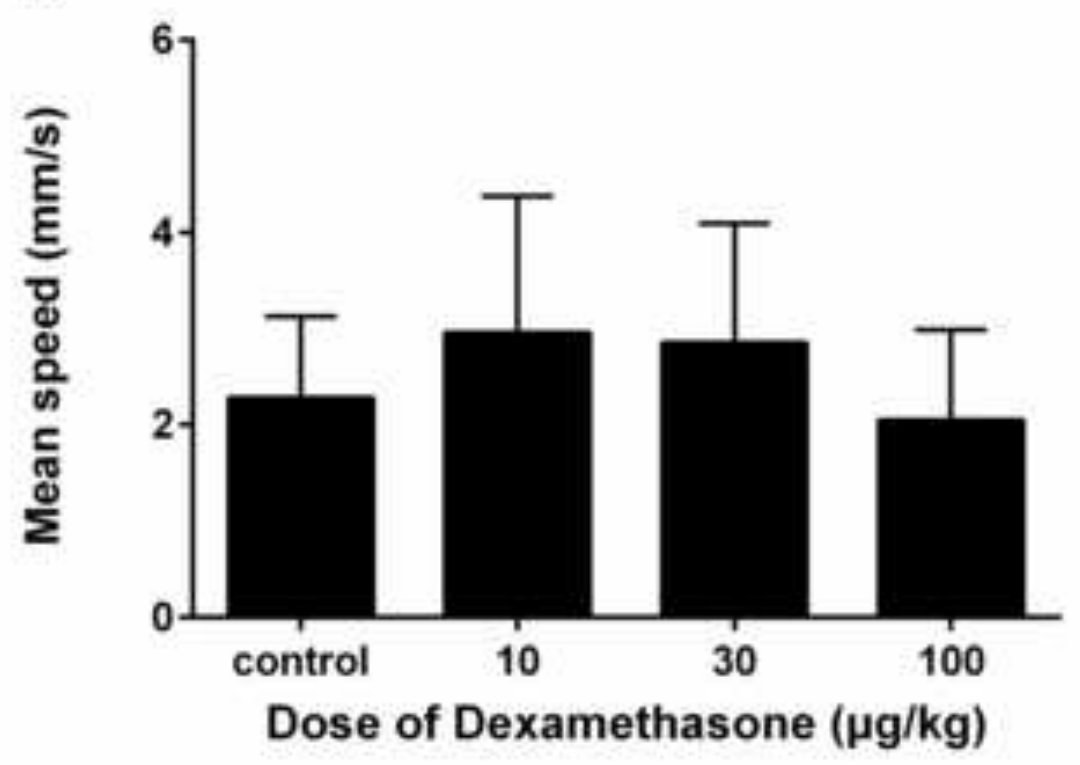


A

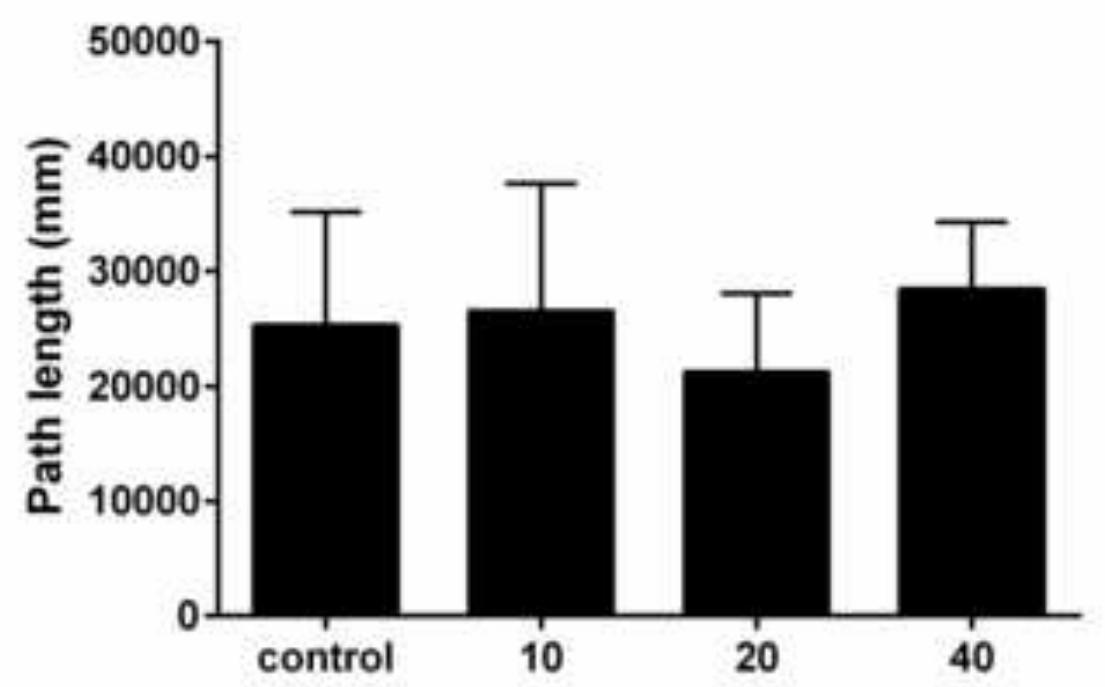

C

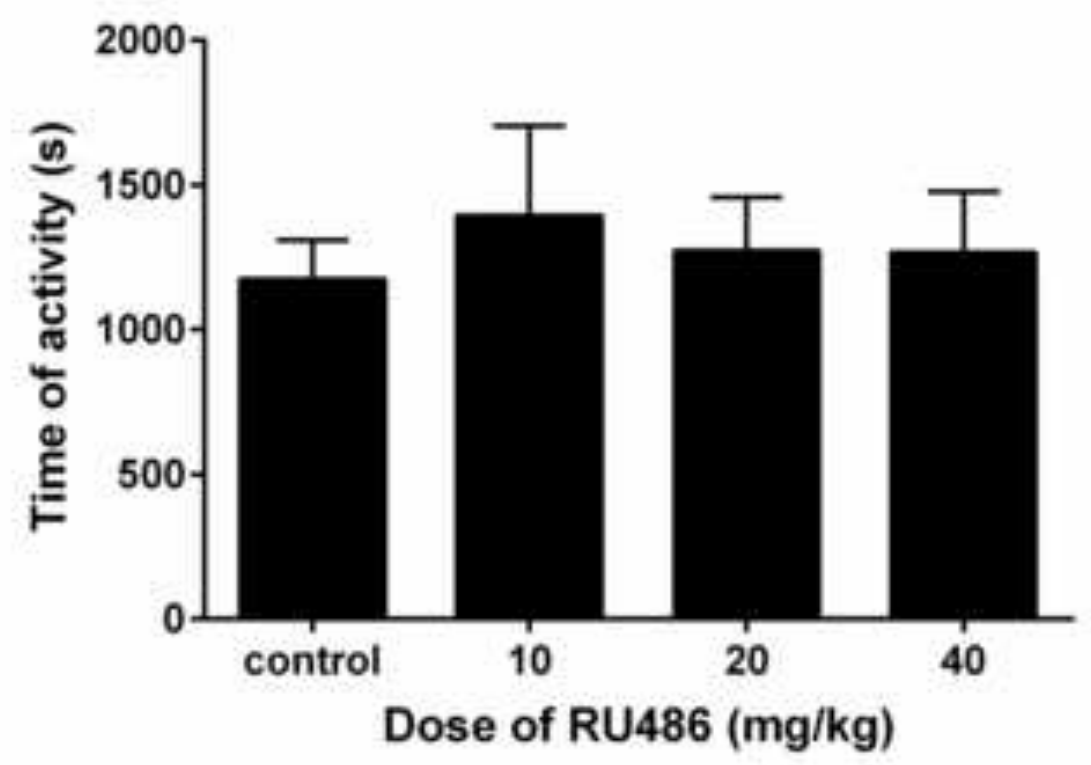

B

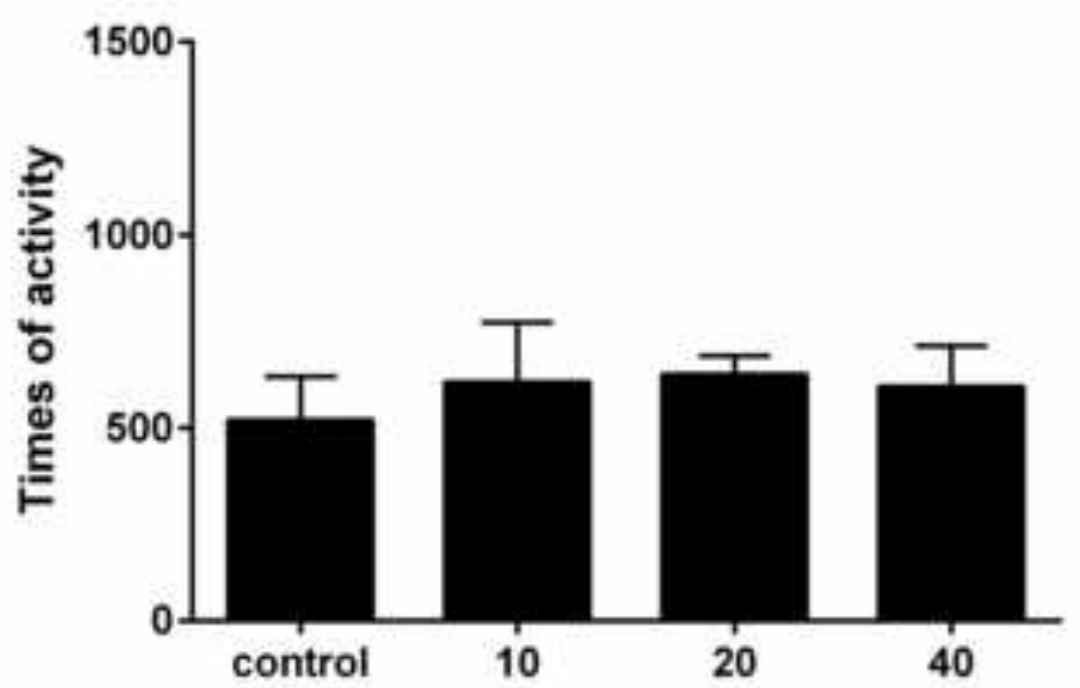

D

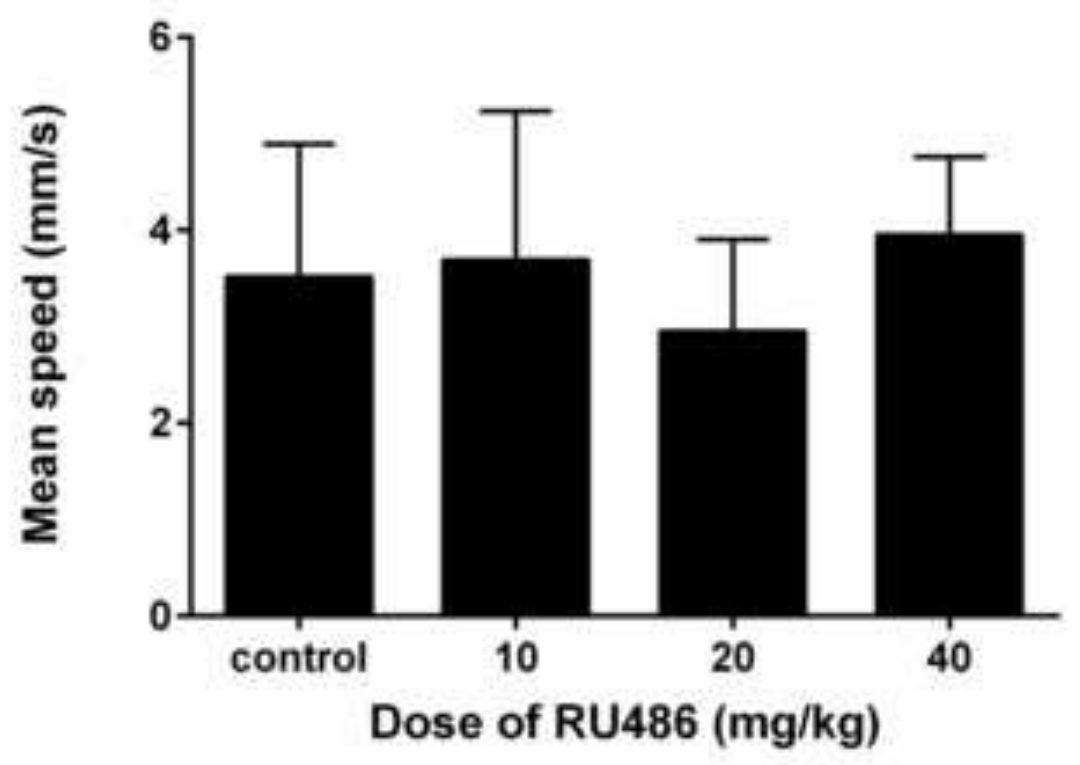


